$\begin{array}{ll} & \text { Etnográfica } \\ \text { etnográfica } & \text { Revista do Centro em Rede de Investigação em }\end{array}$

Antropologia

vol. 24 (2) | 2020

Vol. 24 (2)

\title{
A casa e os altares
}

The house and the altars

\section{Alline Torres Dias da Cruz}

\section{OpenEdition \\ Journals}

\section{Edição electrónica}

URL: https://journals.openedition.org/etnografica/8867

DOI: 10.4000/etnografica.8867

ISSN: 2182-2891

\section{Editora}

Centro em Rede de Investigação em Antropologia

\section{Edição impressa}

Data de publição: 1 junho 2020

Paginação: 351-370

ISSN: 0873-6561

Refêrencia eletrónica

Alline Torres Dias da Cruz, «A casa e os altares», Etnográfica [Online], vol. 24 (2) | 2020, posto online no dia 29 julho 2020, consultado o 20 janeiro 2022. URL: http://journals.openedition.org/etnografica/ 8867 ; DOI: https://doi.org/10.4000/etnografica.8867

\section{(c) (i) (2)}

Etnográfica is licensed under a Creative Commons Attribution-NonCommercial 4.0 International License. 


\section{A casa e os altares}

\section{Alline Torres Dias da Cruz}

Com base em material etnográfico produzido entre pessoas da República Dominicana em Porto Rico, que prestam serviço ritual a espíritos chamados de "mistérios" (que também recebem cuidado de pessoas haitianas), descreverei modos de interiorização de artefatos, imagens e substâncias nos ambientes domésticos para a criação de altares. Discuto como a manipulação desses materiais no interior das casas cria certos efeitos sensíveis nos mistérios, ao mesmo tempo que tenta refazer seus lugares de existência: aqueles referentes ao "tempo" em que os mistérios foram "vivos" ou que recuperam os lugares onde vivem como mortos.

PALAVRAS-CHAVE: altares, casa, artefatos, mistérios, República Dominicana.

The house and the altars - This article is based on ethnographic data about Dominican Republic people which render ritual service to spirits so-called mistérios (that also receive ritual assistance from Haitian people) in Puerto Rico. It will describe ways of interiorizing artifacts, substances and images in order to create altars at home. It discusses how the manipulation of these materials makes as sensory effects on spirits as well tries to rebuild their places of being: those related to time in which mistérios were "alive" or that restore the places where mistérios live as dead.

KEYWORDS: altars, house, artefacts, mistérios, Dominican Republic.

CRUZ, Alline Torres Dias da (linetorresster@gmail.com) - Departamento de Sociologia, Colégio Pedro II, Brasil. 
"ESTA CASA ESTÁ PROTEGIDA, TEM OS SANTOS”, ERA O QUE ROSA DIZIA em quase todas as situações nas quais lhe contavam sobre uma situação envolvendo furto, assalto ou confronto físico onde ela vivia, no bairro de Río Piedras, capital San Juan, em Porto Rico. ${ }^{1}$ Rosa estava em Porto Rico há cerca de dez anos e morava com seus familiares, imigrantes da República Dominicana como ela. Os santos que mencionava eram espíritos chamados de mistérios, concebidos por ela como um "dom de Deus", um ser supremo que estaria acima daquelas entidades. Os mistérios são espíritos que devem ser atendidos ritualmente pelos meus interlocutores dominicanos porque são concebidos como uma herança familiar (Cruz 2014), eles são servidos (alimentados) também pelas pessoas haitianas. ${ }^{2}$

Rosa se reconhecia (e era vista por outros imigrantes da República Dominicana que viviam em Porto Rico) como uma "pessoa que tem os mistérios". Considerava seus mistérios um "dom” porque esses espíritos se comunicavam com ela naturalmente. Ela se concebia como alguém que nasceu com os mistérios. Por isso, distinguia-se de outros seres humanos que, para ela, buscavam se relacionar com esses e outros espíritos intencionalmente. Para Rosa, essa modalidade de relação implicava a compra de espíritos e se opunha ao seu dom natural, duas maneiras de descrever as relações com entidades comuns também aos adeptos da regla de ocha e das reglas del palo em Cuba, conforme Palmié (2002, 2006), e do vodu no Haiti, segundo Richman (2008 [2005]). ${ }^{3}$

Ter os mistérios tinha diferentes implicações na vida de Rosa. Ela trabalhava como comerciante num mercado municipal em Río Piedras. Vendia legumes e frutas em dois quiosques e artefatos e substâncias rituais numa botânica, ocupação que preenchia a maior parte dos seus dias. Durante as vendas na botânica, os mistérios se faziam presentes em suas interações com os clientes. Quando estes se aproximavam da pequena loja do mercado, Rosa os olhava

l Apresento entre aspas termos, expressões e comentários de meus interlocutores, quando em português. As interlocutoras e os interlocutores são nomeados com pseudônimos.

2 Na literatura antropológica sobre o vodu no Haiti, muito mais extensa e antiga que a produção antropológica sobre a República Dominicana (Deive 1975; Alegría-Pons 1993; Davis 1987; Sánchez-Carretero 2005a, 2005b, 2008), tais entidades são chamadas de mystères/mystè (Herskovits 1971 [1937]: 78, 80, 89, 99; Deren 2004 [1953]: 29; Métraux 2007 [1958]: 66); de loa/lwa (espíritos) (Métraux 2007 [1958]: 13, 53; Richman 2008 [2005]: 22; Brown 2001: 5); de senj/sen-yo (santos) (Deren 2004 [1953]: 29; Brown 2001: 6); e ainda de anjos (Brown 2001: 111). Além de mistérios, meus interlocutores usam santos e arcanjos para referirem-se a esses espíritos.

3 Ochoa (2004, 2010: 396) e Espírito Santo, Kerestetzi e Panagiotopoulos (2013: 208, 212) vêm alterando a compreensão antropológica desenvolvida por Palmié $(2002,2006)$ de que o palo monte condensa, em termos de linguagem e técnicas rituais, relações de compra, contrato e violência associadas ao sistema de plantation e ao trabalho escravo em Cuba. Destacam que, no palo monte, densos vínculos de reciprocidade e transformação ontológica são criados entre seres humanos, espíritos e substâncias, reduzindo a ênfase teórica no caráter contratual e na performance ritual do passado colonial e escravista. 
detidamente. Ouvia os problemas que os levavam até ali, geralmente associados à presença de espíritos indesejados ou à falta de atenção ritual com espíritos protetores. Então, indicava-lhes técnicas para afastar os primeiros e estar pendente aos segundos.

Rosa dizia-me que era capaz de fazer isso porque, enquanto os clientes narravam seus problemas, ela via algumas das situações e ouvia as recomendações dos mistérios. Ver, ouvir e também sonhar com os mistérios são modos de incorporação desses espíritos comuns entre os meus interlocutores da República Dominicana. Já a forma mais radical da presença dos mistérios no corpo das pessoas é chamada de "montar". E isso ocorre quando os espíritos entram nas pessoas, transformando-as em "cavalo" dos mistérios (Cruz 2014).

A capacidade divinatória associada aos mistérios também afetava a vida de Rosa e de seus familiares. No entanto, se a presença cotidiana desses espíritos era uma das implicações de seu "dom", para tê-los atuantes era importante que ela lhes prestasse atenção ritual ("atender os mistérios"). Para isso, é fundamental a criação de altares no interior da casa. Casa e altar são domínios aos quais Rosa e outras pessoas da República Dominicana ofereciam rotineiramente atenção e cuidado, porque descobrir-se como uma "pessoa que tem os mistérios" implica a organização doméstica de um altar no qual serviços (alimentos e bebidas), artefatos e outras substâncias são colocados para tais espíritos. Desse modo, os mistérios passam a estar na casa.

Este artigo trata de uma dimensão da atenção ritual: as práticas de interiorização de artefatos, imagens e substâncias na casa de meus interlocutores e os efeitos sensíveis desses "materiais", no sentido de Ingold (2015 [2007] b: 59-60), sobre os espíritos. Pretende salientar que as pessoas da República Dominicana, ao criarem os altares, possibilitam que seus mistérios tenham um engajamento estético e sensorial dentro das casas, uma vez que no interior delas são refeitos seus lugares de existência: referentes ao "tempo" em que os mistérios foram "vivos" ou que recuperam os espaços onde vivem como mortos cultuados atualmente. Cabe pontuar, então, que atender os mistérios cria (mas também atualiza, já que os antepassados familiares assim procederam no passado) relações de intimidade, conhecimento e cuidado com esses espíritos, possibilitando a presença dessas entidades nas casas. Ao mesmo tempo, as pessoas (seus "cavalos") se fortalecem como seres humanos, pois reconhecem que sua energia para a vida resulta da atenção ritual oferecida aos mistérios. O princípio cosmológico entre seres humanos e mistérios enfatiza, assim, relações mútuas, muito embora discordância, desobediência e agressão também possam fazer parte do cotidiano da atenção e cuidado rituais. Logo, mutualidade não implica aqui diretamente domesticação, se por esse termo entendemos um princípio geral a partir do qual se supõe que, devido às suas relações de intimidade e convivência compartilhada, pessoas e espíritos experienciariam entre si uma espécie de suavização ou de acomodação irrestrita e global. 


\section{ENGAJAMENTOS: OS MISTÉRIOS COMO QUADROS}

Em Río Piedras, não muito distante de Rosa, vivia Gina. Numa casa de vila, ela, seu marido e um casal de filhos pequenos compartilhavam a residência com os mistérios. No fundo da casa, um amplo cômodo foi reservado aos santos. Gina tinha imigrado para Porto Rico há cerca de 15 anos. Tomou conhecimento desses espíritos no convívio familiar em Miches, sua cidade na República Dominicana, onde seus avós e sua mãe "trabalharam os mistérios". Isto significa que seus familiares não só atendiam ritualmente, mas também ofereciam consultas a terceiros invocando esses espíritos, e sendo pagos por isso.

Seu contato mais direto com os mistérios, no entanto, ocorreu quando ela começou a sofrer desmaios nas casas em que trabalhava como empregada doméstica e a ser "montada" pelos espíritos em locais públicos, especialmente bares e ruas onde havia consumo de bebida alcoólica, quando já vivia em Porto Rico. Conforme Gina, os mistérios a derrubavam no chão. Circular por botânicas também foi parte desse processo de aproximação e conhecimento dos mistérios. Diante dessas lojas, Gina me disse, ficava sem ação, parada, olhando para os quadros. Assim começou a adquiri-los. Quando a conheci, vários quadros estavam organizados no altar de sua casa; outros se encontravam enfileirados, talvez à espera de atenção e cuidado.

Os mistérios se tornam conhecidos quando "montam" as pessoas, nos sonhos, mas também através de imagens santificadas. Se nos sonhos "se apresentam" (dizem seus nomes) e são vistos e identificados a partir de alguns atributos físicos, vestimentas e adornos, visualizar tais imagens, como Gina me explicou, é outro modo de aproximar-se desses espíritos. Essa pode ser uma experiência sensível avessa a uma inteligibilidade imediata (cf. crítica em Mbembe, 2015); mas pelo menos foi isso o que ocorreu com Gina, que ficava sem ação diante dos quadros à venda, simplesmente observando-os, até dar início à compra desses artefatos. Ainda assim, olhar os quadros dos santos é um modo de as pessoas serem expostas aos mistérios, pois alguns desses espíritos se reconhecem em tais imagens ou fazem referência aos artefatos em suas narrativas. Foram os casos de Ogun Balendyó e Santa Marta A Dominadora.

Ogun Balendyó, um mistério importante para as pessoas da República Dominicana, é o espírito de cabeça de Gina, seu principal mistério, a quem ela chama el patrón (o padroeiro). "Montado" em seu "cavalo", ou seja, em Gina, Ogun Balendyó interage com a imagem de São Santiago Apóstolo. Eu conversava com esse mistério no altar da casa, assim como fiz com outros

4 Os mistérios podem ser masculinos, femininos (chamados de metresas) ou homossexuais. Estão organizados em divisões, com um chefe, e trabalham juntos (mistérios de divisões diferentes "andam" uns com os outros). Essa cosmologia é chamada de 21 División, no singular. 
mistérios durante o trabalho de campo (o que implica que as próprias narrativas dos espíritos incorporados nas pessoas, os quais em algumas situações pediam para conversar comigo, são utilizadas para construir este artigo etnográfico), quando Ogun Balendyó se chamou de Santiago Balendyó. Então, apontou para o quadro de São Santiago Apóstolo e mostrou-me que, na imagem, havia a figura de um homem (vestido com uma armadura sobre um cavalo). Ogun Balendyó me disse: "Ogun Ferraile está sempre atrás de mim. Ele é esse aqui. Ele está sempre atrás de mim, por isso eu pego um lenço (pañuelo) vermelho". Em seguida, procurou entre os quadros do altar outra imagem, para a qual apontou, e disse: "Ele, Ogun Ferraile, é São Jorge".

Um novo engajamento dos mistérios com os quadros ocorreu durante a conversa que tive com a metresa chamada de Santa Marta A Dominadora. Encontrava-me no altar de um casal, também no bairro de Río Piedras, mas numa área mais afastada do centro comercial. Ambos atendiam e trabalhavam os mistérios, assim como fizeram seus familiares dominicanos. Dentro do terreno onde se localizava a casa, também aos fundos, porém num quarto exterior à habitação da família, foi organizado o altar para os mistérios, que assumiu a forma de pirâmide. Como me disse certa vez Gina, esse era o modo certo de fazê-lo.

Conversávamos, quando Maria, a dona da casa, afastou-se da varanda onde ela, Antônio, seu marido, e eu estávamos. Após alguns minutos, Antônio foi até ela. Ao retornar avisou-me que eu deveria acompanhá-lo. Ele me levou ao quarto localizado nos fundos do terreno. Sentada em frente ao altar, organizado com os quadros sobre prateleiras que diminuíam de extensão à medida que a altura aumentava, estava Santa Marta. A metresa havia "montado" Maria. Vestia uma capa roxa e tinha um lenço (pañuelo) preto amarrado à cabeça, adereços que indicavam que ali se fazia presente um espírito que pertence à "divisão dos guedeses". ${ }^{5}$

Chamando-me de "mulher" e "madama", Santa Marta esbravejou diante do altar: "Os seres humanos não creem mais em Deus, não creem mais no próprio ser humano...: Eles [os seres humanos] têm os quadros, usam os quadros, mas...", disse irritada ao olhar para os artefatos no altar. Sem terminar a frase se voltou para Antônio, girou o corpo novamente em direção ao altar, dizendo-lhe que eu falaria com "cada um deles, arcanjos como ela". Então se dirigiu a mim: "Porque tu estás buscando a verdade". Já com a voz mais baixa e tranquila, voltou a afirmar a Antônio que eu retornaria à "casa" e falaria com "cada um deles".

Em seguida, Antônio começou a mostrar-me o altar. Dizendo-me o nome de cada quadro, argumentou: "Para nós [pessoas que têm os mistérios] as imagens

5 Os guedeses são uma categoria de espíritos e formam uma divisão dos mistérios. São os espíritos responsáveis pelos mortos humanos. 
são vivas, eles [os mistérios] estão aqui. Para outra pessoa, isso é um pedaço de madeira, mas, para nós que cremos, isso é vivo" - ele me disse depois de pegar um dos quadros do chão, e reforçou: "Tudo bem, isso é um pedaço de madeira, mas, para nós que cremos, isso é vivo”.

\section{TRANSFORMAÇÕES:}

\section{OS QUADROS COMO COMPOSIÇÕES ATIVAS}

As narrativas de Ogun Balendyó e Santa Marta A Dominadora em suas conversas comigo (e com Antônio, que estava presente no altar no meu encontro com Santa Marta) apontam para o engajamento do mistério e da metresa com os quadros dos santos. E, na medida em que esses espíritos conferem a esses artefatos um caráter performativo (para Santa Marta se os quadros são usados pelos seres humanos é porque tais artefatos são capazes de agir), suas narrativas têm implicações para os estudos antropológicos sobre as práticas rituais afro-caribenhas, especialmente aqueles que, nas últimas décadas, se dedicaram a refletir sobre os modos de incorporação e materialização das entidades no cotidiano dos seres humanos (Palmié 2002, 2006; Richman 2008 [2005]; Ochoa 2004, 2010; Espírito Santo 2009, 2010; Espírito Santo, Kerestetzi e Panagiotopoulos 2013; Wirtz 2014).

No que concerne às narrativas de espíritos, em um artigo sobre a "macumba" carioca, Cardoso (2007: 200-201) propõe que as "estórias" enunciadas por uma preta velha que foi sua interlocutora no Rio de Janeiro possam ser pensadas como atos performativos que constituem as entidades como sujeitos. Nesse sentido, procura compreender as "condições de emergência" dos espíritos como um dos efeitos da própria performance. No entanto, a autora observa que Vovó Cambina, sua interlocutora, não é simplesmente uma história de vida que pode ser isolada, uma biografia sem relação com os atos narrativos, com o próprio narrar (Cardoso 2007: 206-207). Isso a leva a sugerir que a preta velha é "[...] um sujeito que continuamente narra a si mesmo em estórias sobre suas vidas, e que é (re)constituído narrativamente pelos macumbeiros através das histórias de seus feitos e poderes" (Cardoso 2007: 208 - grifo da autora).

As considerações de Cardoso sobre a dificuldade de tomar espíritos como Vovó Cambina como uma história de vida plenamente acessível e inteligível aos seus adeptos (e a ela mesma como antropóloga) são pertinentes para a etnografia que escrevi sobre os mistérios e as pessoas da República Dominicana (Cruz 2014). Como salientei em outro lugar (Cruz 2016: 106), focando não as narrativas, mas os materiais associados aos mistérios que são levados ao encontro e postos em contato por tais pessoas em seu dia a dia, os seres humanos criam mediações e obliterações que evocam antigos modos de socialidade ao manipularem as "coisas dos mistérios". 
Mas destacar o caráter fragmentário e descontínuo (Cardoso 2007: 206) dos espíritos - seja a partir da sua oscilação como sujeito e objeto nos atos narrativos, seja pelo que vem à tona de modo mediado e obliterado com a manipulação humana de suas "coisas" - não resolve os problemas colocados pelas narrativas de Ogun Balendyó e Santa Marta A Dominadora: ambos não se concebem apenas como "sujeitos" que contam suas próprias "estórias", nem atribuem aos seres humanos a exclusividade do engajamento com os artefatos. Eles dizem ser também os quadros, alguns do chamado catolicismo popular, e tais artefatos, para Ogun Balendyó e Santa Marta A Dominadora (mas também para pessoas como Antônio), parecem significar mais do que apenas uma representação.

O mistério e a metresa, parece-me, "problematizam as coisas", conforme sugeriu Rabelo (2014: 192), ao criticar dois modelos teóricos dominantes nas ciências sociais e empregues para a compreensão dos efeitos das "coisas" (particularmente uma pedra, chamada de otá, na qual os orixás do candomblé são fixados) na dinâmica relacional dos terreiros de candomblé. De acordo com Rabelo, os modelos principais mantinham separados os domínios do "não humano e do humano, ou do material e do sentido" (Rabelo 2014: 193), desconsiderando o lugar epistemológico dos objetos, na medida em que seus efeitos seriam apenas projeções da cultura (fonte externa) ou seguiriam leis da natureza (causa e efeito).

Quando realço que os quadros têm um caráter performativo para o mistério e para a metresa, quero salientar que as imagens dos santos e das santas são assuntos de seu interesse. Por isso seriam mais do que projeções de uma cultura ou símbolos do sincretismo religioso (cosmológico) afro-americano (Métraux 2007 [1958]; Apter 2004). Ogun Balendyó, "montado" em seu "cavalo" (Gina), se engaja com a imagem do quadro e se refere ao artefato não exatamente como uma representação de alguma outra coisa. O quadro é transformado em parte do que o espírito também é. Mobilizando um regime visual no qual se mencionam pelo menos duas figuras humanas e seu arranjo (posição) na iconografia, Ogun Balendyó se dá a conhecer. Em sua narrativa o mistério amplia-se a si mesmo ao extrapolar o registro das palavras; com essa observação, não pretendo criar a ideia de que as palavras se opõem às imagens, ou que seriam mais cristalizadas do que as últimas, pois, como observa Espírito Santo, os atos de linguagem mobilizados no espiritismo cubano ativam, criam e intensificam os espíritos que chegam como fluidos (Espírito Santo 2015: 585-586).

O que desejo ressaltar é que, por meio de palavras, esse mistério informa-nos que ele existe para além delas, pois tanto é matéria (um quadro de santo) quanto um arranjo iconográfico: uma disposição na qual estão envolvidas e posicionadas duas figuras de cavaleiros e da qual emerge certa composição, uma forma de visualidade em que estão associados, pelo menos, 
dois mistérios oguns. As propriedades sensíveis do quadro de São Santiago Apóstolo - essa composição visual - transformam o mistério. Ele se torna mais denso e múltiplo, uma vez que não se reduz a simplesmente uma forma espectral (cf. Rabelo 2014: 192-193). "Montar" seus "cavalos", ou seja, fazer-se presente no corpo dos seres humanos (Wirtz 2014: 107, 110 ; Cruz 2016: 99), é apenas uma das modalidades de os espíritos "estarem na casa", como comentou Antônio.

A compreensão de que os mistérios são também os quadros ocorreu na narrativa da metresa Santa Marta A Dominadora. Criticando a apropriação que os seres humanos fazem dos quadros - o que destaca uma das formas materiais como ela e outros mistérios podem existir -, Santa Marta se engajou com esses artefatos e recolocou para mim e Antônio o seu caráter divinizado. Caráter que, para ela, estaria ausente no "uso" das pessoas, que manuseiam os quadros porém não "creem". Em sua narrativa, os mistérios aparecem como entidades objetificadas (são os quadros usados pelos seres humanos) e ativas (o uso de tais artefatos tem implicações para as pessoas, pois argumenta-se que os mistérios são capazes também de agir enquanto quadros e imagens, coisas vivas) a partir de uma relação inapropriada. No entanto, o fato de ela ser um espírito que fala sobre si e outros mistérios, olhando para artefatos maciçamente confeccionados também cria uma extensão de sua presença e agência para além do corpo de Maria. A relevância dos quadros na atenção ritual, para glosar Antônio, não se ressente de que tais artefatos são também madeira, tinta e figuras produzidas em série, pois os mistérios estão também neles à medida que são comprados e levados aos altares, onde às vezes recebem um "santíguo" (modo de consagração que pode ser feito pelos próprios espíritos incorporados em um ser humano) e tornam-se foco de comunicação (pedidos, orações) e alimentação com os serviços rituais.

Podemos supor que ocorre alguma transformação ontológica com a saída dos quadros das botânicas, onde geralmente são comprados, e sua interiorização nos altares domésticos. Convivendo com outros interlocutores dominicanos, ouvia-os falar, como citei acima, sobre "santíguo", um modo de consagração de materiais e artefatos, incluindo bonecos, que conta com a presença dos mistérios "montados" em seus "cavalos". Talvez pudéssemos ir além e considerar que a visualização dos quadros nas botânicas e sua compra já trazem algum nível de afetação (e transformação) de pessoas e mistérios.

No entanto, gostaria, neste texto, de considerar as práticas que possibilitam a "materialização" dos espíritos (Espírito Santo 2009; Wirtz 2014: 100) para refletir sobre as implicações do engajamento dos mistérios com outros artefatos, além dos quadros dos santos. Inicialmente, pretendo destacar como as práticas de interiorização de "coisas" para os espíritos nas casas produzem efeitos sensíveis sobre tais entidades, num processo que, pelo menos do ponto de vista dos mistérios, parece produzir nos altares associações (Espírito Santo, 
Kerestetzi e Panagiotopoulos 2013: 199) e afetações constantes, a ponto de neles serem criadas algumas "paisagens de memórias" (Shaw 2002) espirituais.

\section{EFEITOS SENSÍVEIS}

Após ter recebido a autorização dos mistérios, que quiseram antes saber de Gina se eu realizava a pesquisa para escrever um livro, pude começar a fotografar o altar de sua casa. Certo dia, enquanto fazia as fotos, Gina me disse: "Ogun Balendyó foi um homem de guerra, de batalha, ele me pediu dois cavalos e ferraduras", artefatos que deveriam ser colocados próximos ao seu quadro (de São Santiago Apóstolo) no altar, cada imitação do animal em um dos lados da imagem.

Alguns dias depois Luiz, um amigo de Gina, nascido e criado na Jamaica e que fazia constantemente consultas com Ogun Balendyó, contou-me que a cada encontro com os mistérios no altar levava consigo um presente. Não fazia muito tempo, Luiz me disse que deu uma espada em estilo medieval e com uma longa lâmina e punho de metal para Ogun Balendyó. Ao ver a espada, o mistério lhe disse: "Agora sim eu me sinto como a pessoa que eu era". Depois de repetir para mim o comentário do mistério ao segurar a espada, Luiz me disse satisfeito: "Isso é bonito".

Comentário semelhante me foi feito durante uma visita que realizei a um altar para os mistérios, organizado em uma casa na região metropolitana de San Juan por Armando, um jovem dominicano que é também um "cavalo" desses espíritos. Armando me mostrava as imagens dos santos, quando se deteve em dois chapéus pendurados em uma parede e comentou:

"Esse chapéu azul foi feito especialmente para ele, São Santiago, que me pediu. A capa e o chapéu se parecem com os do quadro de São Santiago. São Santiago, ele conheceu Colombo, tinha conexão. Ele é muito antigo, vem por gerações, vivia em Madri, Espanha. Esse vermelho é de Papa Candelo. Eles [os mistérios] querem sentir-se vivos, querem se ver como eram antes em cabeça humana, se vestiam assim antes. Eles viviam assim com essa roupa”.

O pedido de Ogun Balendyó à Gina, ao qual ela respondeu comprando os cavalos em miniatura, e o cuidado com as cores e materiais dos chapéus que Armando conferiu ao mesmo mistério e a Candelo Sedifé, fazem parte do cotidiano da atenção ritual. Um cuidado estético, já que a atenção das pessoas precisa estar voltada para cores, tecidos, materiais e formatos específicos de adereços e vestimentas, além de envolver a interação diária delas com seus espíritos herdados. Contudo, associar cavalos em miniatura, espada e chapéus junto aos quadros dos santos - ao lado, diante, atrás - torna-se um ofício singular. 
Promovendo dentro das casas esses arranjos entre artefatos variáveis - as "coisas dos mistérios" -, Gina, Armando, e Luiz procuram refazer antigas experiências mundanas de Ogun Balendyó (e de outros mistérios e metresas). Com esses arranjos artefactuais, meus interlocutores conseguem, provisoriamente, trazer à tona a sensação de vida em seus espíritos herdados. Em contato com uma espada, Ogun Balendyó rememora a sensação de ter sido uma pessoa ("vivo"), assim como se mantém como um espírito protetor, pois recebe atenção e cuidado. As pessoas, por sua vez, podem conhecê-lo a partir de um arranjo iconográfico ou usá-lo ritualmente sob essa forma. Nesse sentido, sugiro que, tal como os quadros de santos, espadas, objetos em miniatura e figuras de gesso não são exatamente coisas acabadas, cristalizadas no mundo, mas artefatos que, do ponto de vista dos mistérios e das pessoas, podem ativar antigas (e novas) relações e sensações.

"São Elias me pediu uma cobra, mas eu lhe disse que vou comprar uma de mentira. Eu tenho as crianças aqui...", Gina me disse ao chamar a atenção para um dos pedidos que esse mistério lhe fez. E ela continuou: "São Elias gosta da terra". Por isso, me explicou, é importante passar na terra (e não lavar) a xícara com café colocada como serviço (ritual) para ele. Os pedidos e "gostos" de São Elias, também conhecido como Barão do Cemitério, foram maximizados em outro altar que visitei na cidade de San Juan. No interior da casa de Raul, em um dos cômodos onde foi criado o altar, São Elias foi servido com um amplo prato de arroz e feijão (moro con habichuelas), arenque (peixe), pão de mandioca (cassava) e ovo cozido. A esses alimentos foram combinados outras substâncias e artefatos: o serviço foi posto em frente a um esquife talhado com uma cruz ao centro. Sobre a pequena tumba, foi posicionada uma panela com terra de cemitério; ao lado da tumba, havia uma imagem em gesso do santo e uma garrafa de bebida alcoólica praticamente vazia.

\section{PAISAGENS DE MEMÓRIA ESPIRITUAIS}

$\mathrm{Na}$ atenção ritual a São Elias, Gina e Raul, além de alimentar o mistério, lidam com a tarefa, por vezes insólita, de recriar a paisagem (Shaw 2002) fúnebre na qual ele se encontra. A partir desse caso, mas também daqueles já descritos, é possível sugerir que o conhecimento sobre os materiais e a competência de ofertá-los são uma competência geral da "pessoa que tem os mistérios". Pois essa, em seu cotidiano, tem como tarefa buscar responder a expectativas institucionalizadas sobre os modos adequados de produzir correspondências tangíveis dentro de suas casas para os mistérios: entidades que circulam e ocupam, sob formas diversas, o mundo que "os vivos chamam de Terra". Isso nos sugere não necessariamente a existência de mundos específicos e separados para seres humanos e mistérios. Mas, antes, que há percepções e experiências 
diferenciadas em domínios que, do ponto de vista das pessoas, são concebidos como uma única dimensão, total e global: a Terra.

Para meus interlocutores da República Dominicana, a primeira tumba de um campo santo é lugar de atenção e trabalho rituais com São Elias. "Montado" em seu "cavalo" (Armando), São Elias se apresentou para mim dizendo: "Eu me chamo o Barão do Cemitério, espírito de um morto, tu me entendes, tu me entendes? Espírito de um morto, que cuida dos mortos em acidentes trágicos e... mortos em acidentes de carro", o que o torna um mistério da divisão dos guedeses. São Elias/Barão do Cemitério me explicou ainda por que, ao redor da sua imagem e de seus artefatos, há sempre um frasco de talco. Com a voz rouca e sussurrando, ele disse gostar do frio, possuir a pele fria (quando "monta" uma pessoa). E o talco lhe serve para manter a temperatura adequada: aquela de um morto humano enterrado em um cemitério.

Temperatura e textura, associadas ao contato de recipientes com a terra, a um esquife e ao uso do talco, permitem a recriação de uma ambiência fúnebre dentro dos altares domésticos. Aqui, os artefatos e as substâncias agregadas são interiorizados pelas pessoas na tentativa de refazer para São Elias não exatamente o que foi a experiência de ter sido uma pessoa, como ocorre com Ogun Balendyó.

Essa atenção das pessoas à variação de temperatura e de textura das substâncias é também importante para os mistérios conhecidos como "indios". Gina, por recomendação de Ogun Balendyó, cobriu com farinha de milho uma área do chão do altar sobre a qual ficavam as imagens de índios e índias. Seu patrono ensinou-lhe que esses espíritos gostam de ter essa substância próxima. Tanto no altar organizado por Gina quanto no de Armando, as imagens da "divisão índia" são de importantes personagens históricas no confronto e na oposição à invasão e à ocupação espanhola no início do século XVI. ${ }^{6}$

Em um nível acima do chão do altar, numa espécie de mirante, Gina arranjou os quadros da chefe indígena Anacaona, que teria vivido no que hoje é o Haiti, do cacique Guacaipuro, que habitou a região de Los Teques, na Venezuela, e de um espírito chamado de Negro Felipe. ${ }^{7}$ Pequenos artefatos como uma coruja em miniatura em frente de uma imagem de um índio em posição de observação, uma guimba de tabaco, uma xícara de café e outra com um tostado (grãos como milho e gergelim) parecem funcionar (Espírito Santo, Kerestetzi e Panagiotopoulos 2013), junto aos quadros, como índices não apenas da presença, mas também das lembranças dos próprios mistérios, que, talvez, assim se sintam como eram "quando vivos".

6 Especialmente na ilha chamada de Hispaniola, depois transformada em Haiti e República Dominicana, e na região centro-norte do que se tornou a Venezuela.

7 Conforme meus interlocutores da República Dominicana, os três recebem atenção ritual na Venezuela e são conhecidos como as Três Potências. 
Já Armando explicou-me que seu altar índio foi feito em um corredor separado de onde se encontra o altar principal. Naquele corredor o chão era pavimentado com cimento. No entanto, Armando precisou desfazer esse piso: retirou o cimento e deixou que a terra ficasse exposta. Com essa desmontagem, uma nova paisagem foi criada para os mistérios índios. E ele me explicou: "Para os mistérios é bom que eu viva num lugar como esse ['um campito']. Porque os mistérios gostam de umidade, de terra, de sentir o cheiro da terra, porque isso os atrai, eles sobem mais rápido".

Além disso, acrescentou que os mistérios gostam de ter perto uma árvore de guando, a qual foi plantada numa área íngreme em frente de sua casa. Atrás da moradia, havia ainda um lago com crocodilo, peixes, caranguejos e cobras. Antes de ir viver nesse município da região de metropolitana de San Juan - uma antiga região de usina de cana de açúcar -, Armando morava em uma "urbanização" mais próxima da capital porto-riquenha. Mas, conforme ele, isso "não é bom para os mistérios".

O espírito da divisão dos petroses chamado de Gran Toroliza é atendido por Gina sobre a mesa principal do altar, ainda que os mistérios dessa categoria geralmente peçam seu "serviço" no chão, o que em alguns altares é oferecido contíguo ao dos guedeses. Ele vive no "monte" e seu quadro é o de Jesus da Boa Esperança (um Cristo sentado em uma cadeira construída com estrados de madeira). Gina e eu íamos até a escola de seus filhos, quando ela me disse que estava na casa da irmã no momento que precisou ir até o quintal (patio) para que esse espírito "montasse". Quando colocaram uma cadeira para o espírito se sentar, o móvel se rompeu com o peso dele: "Ele é muito forte", ela salientou. "Ele é bem bravo, sobe no 'monte', em uma casa com palo [varas de madeira] atrás, fora da casa". 8

\section{ALGUMAS IMPLICAÇÕES ARTEFACTUAIS}

Os arranjos e as combinações que são feitos e desfeitos pelas "pessoas que têm os mistérios" procuram seguir pelo menos duas coordenadas espaciais: terra e ar. É comum que, ao entrar num altar para os mistérios, alguém depare com quadros de santos colocados no chão e outras imagens sobre uma mesa (ou

8 A paisagem do "monte" está ligada, em várias ilhas caribenhas (Haiti, Suriname, Jamaica, Cuba, República Dominicana, Porto Rico, Guadalupe, Martinica), à presença e ocupação das áreas de mato, bosque e montanhas pelos chamados cimarrones, escravos africanos e crioulos que não se submetiam ao poder colonial e fugiam para regiões isoladas e de difícil acesso, e que podiam também entrar em confronto direto com os exércitos coloniais. Entre os meus interlocutores dominicanos, a divisão dos petroses é concebida como a dos espíritos que em vida se estabeleceram no "monte". Esses espíritos são definidos por comportamentos violentos, intransigentes e "rebeldes". Historicamente, foram associados às vitórias dos escravos crioulos e africanos em Saint Domingue (atual Haiti) sobre o domínio colonial francês. 
diferentes móveis). E as próprias pessoas, quando conversam sobre isso, referem-se aos espíritos como "santos da terra" e "santos de cima". Alguns altares são organizados semelhantes a uma pirâmide. Outros são criados seguindo uma distinção entre níveis de altura, mas produzindo uma espécie de contiguidade entre uma e outra paisagem espiritual.

Os "santos da terra" são considerados negros e negras, geralmente são identificados como guedeses: São Elias/Barão do Cemitério é visto pelos seres humanos como um homem trigueño (mulato de pele escura) nos cemitérios; Santa Marta A Dominadora é concebida como uma mulher negra; e Guedé Limbó, como um homem negro que se comporta como um pedinte. Esses são os guedeses mais populares entre meus interlocutores da República Dominicana. Mas nem todos os mistérios que estão na terra, ou seja, arranjados no chão, são guedeses. Para meus interlocutores dominicanos, o "gosto" de alguns guedeses pela terra é uma disposição que estes mistérios trazem de suas antigas experiências de vida. Outra divisão, chamada de petroses, é caracterizada como próxima da terra, e vários de seus quadros são organizados no chão dos altares, às vezes ao lado dos guedeses.

Entre os chamados "santos de cima", há mistérios que pertencem à divisão dos ogunes, como Ogun Balendyó/São Santiago Apóstolo, que "andam” ou "trabalham juntos", como Belié Belcan/São Miguel Arcanjo e Papa Candelo (Candelo Sedifé), e mistérios femininos chamados de metresas, que estão ao lado dos mistérios masculinos. Alguns são descritos pelos interlocutores através de seus artefatos, e também de seu paladar: aquilo de que se alimentam, a quantidade a ser oferecida e o modo como isso deve ser colocado aos espíritos nos altares diferenciam os "santos do chão" e "de cima". Joana, uma de minhas interlocutoras, explicava-me que: "Eles [os guedeses] gostam de comer na figueira [cabaça da árvore]. Eles gostam do chão, da terra, não gostam do luxo. Há mistérios que gostam do luxo, mas os guedeses, não. Eles gostam de comer na figueira, que se fume seu tabaco... São Miguel e Anaísa gostam de 'finura', gostam de bolo".

Enquanto os mistérios "guedeses estão na terra", podem ser servidos em cabaças e manifestam uma disposição maior para o consumo, os "santos de cima”, como São Miguel Arcanjo/Belié Belcan, Santa Ana/Anaísa, São Santiago Apóstolo/Ogun Balendyó, Virgem Dolorosa/Metresili, e Papa Candelo (Candelo Sedifé), manifestam uma disposição alimentar mais minimalista em relação àqueles e geralmente são servidos à mesa. Com certo constrangimento, Gina me contou que Santa Marta A Dominadora "gosta" de ovo e beringela crus, café, leite, além de fumar tabaco. Para Gina, esse paladar se associa ao da cobra, animal com o qual Santa Marta se hibridiza, o que leva as pessoas a se rastejarem (se menear) pelo chão no processo em que a metresa as "monta". Já São Miguel, Anaísa e Metresili, por causa de sua "finura", pediam pães (mas não à base de mandioca - cassava - como os guedeses), 
cerveja (bebida preferida de Anaísa), refrigerante açucarado (do "gosto" de Metresili), frutas e doces.

Parece-me equivocado, no entanto, argumentar que as coordenadas espaciais que marcam em linhas gerais a organização dos altares domésticos cristalizam apenas uma hierarquia sociorracial caribenha e seus espaços/lugares ritualmente incorporados. Se, por um lado, as descrições que apresentei demonstram o pertencimento social, cultural e racial dos mistérios, como certa vez São Elias/Barão do Cemitério me disse, ao afirmar que "todo mistério tem uma história, uma cultura”, do ponto de vista da prática da atenção ritual, tanto esse pertencimento quanto as paisagens parecem implicar mais do que memórias incorporadas, como sugeriu Shaw (2002). ${ }^{9}$

Em sua etnografia sobre as cosmologias e práticas rituais da comunidade Temne de Serra Leoa - envolvida nas rotas do tráfico transatlântico de escravos africanos -, Shaw (2002: 56) faz uma contribuição importante ao trazer para a reflexão antropológica os espaços e as geografias de Serra Leoa a partir das memórias cristalizadas e experienciadas nesses lugares por seus interlocutores, lançando mão da noção de "paisagens mnemônicas". Seu foco nas transformações cosmológicas e técnicas rituais associadas aos lugares oferece uma reflexão interessante sobre as práticas de incorporação dos espíritos para além da dimensão estritamente corporal.

Com base nas descrições apresentadas na seção anterior, é importante observar que as práticas de atenção ritual voltadas à recriação de paisagens de memórias espirituais são um modo de trazer à tona lembranças sensoriais nos espíritos: são eles que se relembram, por meio das sensações que emergem quando em contato com alguns artefatos, substâncias e seus arranjos, o que era sentir-se humano, não as pessoas cujo ofício singular é justamente permitir esse engajamento estético e sensorial de seus mistérios. Sugiro que, nesse ofício pessoal de refazer no interior das casas paisagens significativas para os espíritos, o que está em jogo é mais do que experiências históricas condensadas em lugares, como apontou Shaw, e num certo sentido Palmié (2002), ao refletir sobre a imagem que as ngangas das reglas del palo assumem, assemelhando-se aos palenques.

No caso da atenção ritual dos mistérios, lugares como cemitérios, geografias indígenas e o "monte" precisam ser recriados no mundo dos seres humanos, dentro das casas das pessoas. Estas produzem nos espaços domésticos modos de existências dos espíritos em que a densa e difícil ambientação é uma tarefa com a qual elas precisam lidar em seu cotidiano. Com essas composições

9 Embora ele mesmo seja cultuado independentemente do que possa ter sido seu modo de vida enquanto ser humano. 
artefactuais, deseja-se trazer à tona a densidade de existências que não estão alijadas de incrustações espaciais. ${ }^{10}$

Isso parece ocorrer na atenção ritual que Raul presta a São Elias/Barão do Cemitério. Nela, é possível apontar que o que se busca refazer são as condições sensoriais do espírito de um morto humano enterrado em um campo santo: a temperatura fria e as sensações táteis do contato com a terra. E a produção de outras qualidades sensíveis nos altares parece ocorrer na escavação de Raul, oferecendo umidade e odor de terra aos mistérios índios. Contudo, proponho que essa paisagem fúnebre não é refeita, do ponto de vista do mistério, como um cenário fixo. Ela se torna uma ambiência, uma vez que tudo o que as pessoas manipulam e combinam nos altares para São Elias age sobre ele, o mantém no interior das casas e compõe o que ele é. Enfatizar essa dimensão sensível das paisagens espirituais, dos lugares nos quais os mistérios estão para além da (e na) casa, permite também uma reflexão sobre a importância de uma percepção espacial na compreensão dessas entidades.

As pessoas da República Dominicana com as quais convivi em Porto Rico fazem referência ao fato de que os mistérios precisam "chegar" às casas. Alternam a noção de "montar" com a de "subir": "um mistério vai subir", "subiu um mistério", são expressões comuns para retratar a presença dos espíritos no corpo dos seres humanos. Após ter escutado essas considerações diversas vezes, perguntei à Gina de onde esses espíritos sobem. "Da terra, do ar", ela me respondeu, porque os mistérios são humo (fumaça); "eles estão por aí", diziam os clientes dominicanos que frequentavam as botânicas.

Tendo conhecimento dessa característica inconstante dos mistérios, pessoas como Armando e Gina aprenderam que cuidar e invocar tais espíritos - geralmente para o trabalho ritual - dependem da capacidade de afetá-los. Aqui, é possível sugerir que meus interlocutores aprendem também a competência de receber, de saber cuidar e de criar bem-estar - uma hospitalidade -, pois lidam (e administram artefactualmente) com agências, temporalidades e espacialidades diversas. De modo que das relações e práticas rituais com seus mistérios gesta-se uma socialidade mais abrangente, em que ser hospitaleiro é relevante. Daquelas relações e práticas vem a possibilidade de os mistérios chegarem a suas casas, de "subirem" ou "montarem" seus corpos para interagir com

10 Isso, contudo, não significa que os mistérios estão sob o controle absoluto das pessoas porque ocupam as casas, tampouco que as pessoas, por atenderem seus múltiplos pedidos, se sintam protegidas da punição e vingança de seus espíritos herdados. No interior dos altares agressões verbais e físicas, entre seres humanos e mistérios, são passíveis de acontecer e marcar - inclusive corporalmente - as "pessoas que têm os mistérios". Neste sentido, domesticação, como um termo amplo e irrestrito que nos informaria sobre a natureza dos vínculos aqui descritos, parece não dar conta da densidade etnográfica em jogo. Seria mais produtivo, assim, pensar, com base no material etnográfico, em atos de domesticação específicos entre certos interlocutores e determinados mistérios, mas não isso enquanto um princípio geral. 
familiares e clientes, e nelas permanecerem. Na casa os mistérios "comem", mas também podem se sentir como eram no seu "tempo". Fora dela, são vistos sobre as pedras dos rios, dentro do mar, em alturas medianas (suspensos do solo), no cemitério, no "monte" e no céu.

Nesse sentido, organizar os altares parece ser uma tarefa que permite que os mistérios cheguem, mas que também permaneçam nas casas. Conforme São Elias, "O altar é um símbolo de atração [...] tranquiliza o 'cavalo', pois os mistérios estão na casa, ele não pode, o 'cavalo', trabalhar em outro lugar”. Essa coabitação, no entanto, parece se tornar possível na medida em que no decorrer da circulação dos mistérios, que "estão por aî", são "fumaça", as pessoas se esforcem para estabilizar e sedimentar seu dom espiritual: ouvindo os conselhos dos espíritos, sonhando com eles, sendo "tocadas" por suas imagens (quadros) e interiorizando artefatos, associando-os e recriando efeitos e condições sensoriais nos espíritos, suas paisagens espirituais.

Se, para isso, a atenção a variações de temperatura, a profundidade, a textura, os odores e a maximização de vitalidade (consumo) espiritual são fundamentais, é possível sugerir que esses aspectos sensíveis são agenciados pelas pessoas como certas formas diferenciadas de socialidade: ambiências que revelam mais do que espíritos individualizados que precisam ser "materializados", como sugeriu Espírito Santo (2009), uma vez que as entidades parecem se vincular e se associar a composições múltiplas e complexas: longe de discretas, estas parecem ser produzidas em contatos, trocas, afetações e efeitos ambientais.

\section{CONSIDERAÇÕES FINAIS}

Neste artigo, apresentei descrições etnográficas sobre a interiorização nos espaços domésticos de artefatos e substâncias por pessoas da República Dominicana que vivem em Porto Rico, no Caribe. Tais práticas buscam atender ritualmente os mistérios, seus espíritos herdados familiarmente.

Iniciei o texto destacando a relevância dos artefatos e seus arranjos nos altares para os mistérios. Se, na literatura sobre as religiões afro-americanas (Herskovits 1971 [1937]; Métraux 2007 [1958]; Deren 2004 [1953]; Brown 2001; Palmié 2002; Richman 2008 [2005]; Ochoa 2004, 2010), a alimentação ritual foi uma prática importante na compreensão dos diversos vínculos criados entre seres humanos e agências espirituais, no artigo procurei dar relevo aos efeitos sensíveis que as "coisas dos mistérios" produzem nessas entidades. Busquei dar saliência à dimensão material deslocando-a de sua compreensão como um domínio encerrado e bem delimitado, exterior aos espíritos, às pessoas e com qualidades estáveis. Victor Turner (2005 [1967]: $450,453)$, em seu relato etnográfico sobre o que chamou de "ritual de aflição" entre o povo $\mathrm{Ndembu}$, já havia salientado, por exemplo, o que pode ser visto 
como a importância da "materialização" de elementos complexos da relacionalidade em objetos tangíveis. O ihamba era um objeto ritual confeccionado a partir dos dentes incisivos superiores de caçadores que usavam arma de fogo e herdados pelos parentes adequados de um caçador morto, que deveriam ser iniciados no culto específico. Para os Ndembu, o objeto preservava boa parte do poder dos caçadores de matar animais. E, para ter eficácia, deveria ser combinado a panos, incluindo os do caçador morto, colocado em contato com alimento e sangue animal, carregado em uma bolsa (mukata) e possuir búzios que se tornavam olhos da sombra do caçador. Pelos olhos do ihamba, a sombra do caçador era capaz de "ver os animais" na floresta e transmitir esse poder ao dono do objeto ritual.

Nas descrições apresentadas, os mistérios se apropriam dos artefatos, transformando-se neles também; reconhecem a potência dos quadros de santos e santas no cotidiano das pessoas, bem como o estado objetificado que podem assumir quando são "usados" por elas; e, inusitadamente, querem entrar em contato com certas "coisas" para recuperar suas lembranças sensíveis. Há uma dimensão ativa da atenção ritual, pois os artefatos são importantes, para os mistérios, de um ponto de vista estético e sensorial, e, mais importante ainda, relacional, pois ao serem combinados e arranjados de modos singulares, recriam e ativam antigas relações e experiências, o que possibilita aos espíritos sentirem-se como eram "quando vivos".

O arranjo dos artefatos nos altares domésticos pelas pessoas também ressalta a multiplicidade dos mistérios. A capacidade de povoarem o mundo como formas diversas, sendo espírito e matérias (fumaça, corpos, quadros), e, neste sentido, de se transformarem sem se encerrar em uma única forma, permite que pensemos os mistérios como agências também artefactuais. Embora "venham por gerações" nas famílias (sejam espíritos muito antigos e transmitidos), como me disse Armando, os mistérios dependem das composições recriadas pelas pessoas no interior das casas para continuar existindo. Esse parece ser o caso do que chamei de paisagem de memórias espirituais. Ao se dedicarem ao ofício singular de atendê-los, as pessoas não associam apenas artefatos e substâncias nos altares, mas também os manuseiam no sentido de produzir profundidade, textura, temperatura e odores propícios à ambientação dos mistérios dentro das casas. Neste sentido, parecem se aproximar em certa medida de Ingold (2015 [2007] b: 63), no artigo "Materiais contra materialidade", quando propõe: "Trazer coisas à vida, portanto, não é uma questão de acrescentar a elas uma pitada de agência, mas de restaurá-las aos fluxos geradores do mundo de materiais no qual elas vieram à existência e continuam a subsistir". Com isso, o que as pessoas são capazes de refazer não se restringe a espíritos discretos e histórias cristalizadas, uma vez que parece se tratar da recriação, como um modo de vivificação, de socialidades que não se separam de espaços e lugares igualmente espectrais. As implicações, para as pessoas, dessas práticas 
artefactuais fundadas nas narrativas de espíritos (e outras experiências sensíveis como a visualização dos quadros e os sonhos) e na manipulação de artefatos, substâncias e materiais interiorizados no espaço, leva-nos a pensar naquilo que Lévi-Strauss (1967: 230) chamou de "ad-reação" na discussão sobre o xamanismo cuna. Ainda que fazendo uso de uma analogia com a psicanálise, o autor sinaliza o papel da cura xamanística de provocar uma experiência e, neste processo, reconstituir um mito que será vivido ou revivido pela doente, mas cujo autor e protagonista é o próprio xamã. No material etnográfico que descrevi e sobre o qual procurei refletir, é na casa ocupada pelos altares, pelos mistérios e pela ambiência performatizada por alguns desses espíritos que as pessoas podem experienciar, de modo sincrônico e mediado, relacionalidades constituídas por arranjos de artefatos, substâncias, sensações, profundidade, altura, temporalidades e espacialidades.

\section{BIBLIOGRAFIA}

ALEGRÍA-PONS, José F., 1993, Gagá y Vudú en la República Dominicana: Ensayos Antropológicos. Porto Rico/Santo Domingo, Ediciones El Chango Prieto.

APTER, Andrew, 2004, "Herskovitis's heritage: rethinking syncretism in the African diaspora”, em Anita Leopold e Jeppe Jensen (orgs.), Syncretism in Religion: A Reader. Londres, Equinox, 160-184.

BROWN, Karen McCarthy, 2001, Mama Lola: A Vodou Priestess in Brooklyn. Berkeley e Los Angeles, University of California Press.

CARDOSO, Vânia Zikán, 2007, "O espírito da performance", Ilha: Revista de Antropologia, 9 (1): 198-213.

CRUZ, Alline Torres Dias da, 2014, Sobre Dons, Pessoas, Espiritos e Suas Moradas. Rio de Janeiro, Universidade Federal do Rio de Janeiro, tese de doutorado em Antropologia.

CRUZ, Alline Torres Dias da, 2016, "Manipulando socialidades: pessoas, mistérios e prestações rituais”, Cadernos de Campo, 21: 95-109.

DAVIS, Martha Ellen, 1987, La Otra Ciencia: el Vodú Dominicano como Religión y Medicina Populares. Santo Domingo, Universidad Autónoma de Santo Domingo.

DeIVE, Carlos Esteban, 1975, Vodu y Magia en Santo Domingo. Santo Domingo, Museo del Hombre Dominicano/Colección Departamento Ciencias Sociales, série Antropología Cultural.

DEREN, Maya, 2004 [1953], Divine Horsemen: The Living Gods of Haiti. Nova Iorque, McPherson \& Company.

ESPÍRITO SANTO, Diana, 2009, Developing the Dead: The Nature of Knowledge, Mediumship, and Self in Cuban Espiritismo. Londres, University College of London, tese de doutorado. 
ESPÍRITO SANTO, Diana, 2010, "Spiritist boundary-work and the morality of materiality in Afro-Cuban religion”, Journal of Material Culture, 15 (1): 64-82.

ESPÍRITO SANTO, Diana, 2015, "Liquid sight, thing-like words, and the precipitation of knowledge substances in Cuban espiritismo", Journal of the Royal Anthropological Institute, 21 (3): 579-596.

ESPÍRITO SANTO, Diana, Katerina KERESTETZI, e Anastasios PANAGIOTOPOULOS, 2013, "Human substances and ontological, transformations in the African-inspired, ritual complex of Palo Monte in Cuba", Critical African Studies, 5 (3): 195-219.

HERSKOVITS, M. J., 1971 [1937], Life in a Haitian Valley. Nova Iorque, Anchor Boooks.

INGOLD, Tim, 2015 [2007] a, Estar Vivo: Ensaios sobre Movimento, Conhecimento e Descrição. Petrópolis, Editora Vozes.

INGOLD, Tim, 2015 [2007] b, "Materiais contra materialidade", em Tim Ingold, Estar Vivo: Ensaios sobre Movimento, Conhecimento e Descrição. Petrópolis, Editora Vozes, 49-69.

LÉVI-STRAUSS, Claude, 1967, "A eficácia simbólica”, em Claude Lévi-Strauss, Antropologia Estrutural. Rio de Janeiro, Tempo Brasileiro, 215-236.

MBEMBE, Achille, 2015, "O tempo que se move", Cadernos de Campo, 24: 369-397.

MÉTRAUX, Alfred, 2007 [1958], Le vaudou Haïtien. Paris, Gallimard.

OCHOA, Todd Ramon, 2004, The Dead and the Living in a Cuban-Kongo Sacred Society. Nova Iorque, Columbia University, tese de doutorado.

OCHOA, Todd Ramon, 2010, "Prendas-Ngangas-Enquisos: turbulence and the influence of the dead in Cuban-Kongo material culture", Cultural Anthropology, 25 (3): 387-420.

PALMIÉ, Stephan, 2002, Wizards and Scientists: Explorations in Afro-Cuban Modernity and Tradition. Durham e Londres, Duke University Press.

PALMIÉ, Stephan, 2006, "Thinking with Ngangas: reflections on embodiment and the limits of 'objectively necessary appearances' ", Comparative Studies in Society and History, 48 (4): 852-886.

RABElO, Miriam, 2014, Enredos, Feituras e Modos de Cuidado. Dimensões da Vida e da Convivência no Candomblé. Salvador, Editora da Universidade Federal da Bahia.

RICHMAN, Karen E., 2008 [2005], Migration and Vodou. Gainsville, FL, University Press of Florida.

SÁNCHEZ-CARRETERO, Cristina, 2005a, "Santos y misterios as channels of communication in the Diaspora: Afro-Dominican religious practices abroad", Journal of American Folklore, 118 (469): 308-326.

SÁNCHEZ-CARRETERO, Cristina, 2005b, "Transnational devils: nicknames and document identities as survival strategies in the context of Dominican migration", Folks Art: Croatian Journal of Ethnology and Folklore Research, 1: 65-83.

SÁNCHEZ-CARRETERO, Cristina, 2008, "La creencia en la 'no-creencia' de los espíritus y otras cartografías de lógicas religiosas: el caso de los centros de portadoras de misterios dominicanos en Madrid”, em M. Cornejo, M. Cantón e R. Llera Blanes (orgs.), Teorías y Prácticas Emergentes en Antropología de la Religión. S./l., Ankulegi Antropologia Elkartea, 253-272.

SHAW, Rosalind, 2002, Memories of the Slave Trade: Ritual and the Historical Imagination in Sierra Leone. Chicago e Londres, The University of Chicago Press.

TURNER, Victor, 2005 [1967], "Um curandeiro ndembu e sua prática”, em Victor Turner, Floresta de Símbolos: Aspectos do Ritual Ndembu. Niterói, Editora da Universidade Federal Fluminense, 449-488. 
WIRTZ, Kristina, 2014, "Spiritual agency, materiality, and knowledge in Cuba", em Paul Christopher Johnson (org.), Spirited Things: The Work of "Possession" in Afro-Atlantic Religions. Chicago e Londres, The University of Chicago Press, 99-129.

Receção da versão original / Original version $2018 / 01 / 19$

Aceitação / Accepted $2019 / 11 / 18$ 